\title{
Synthesis of boron nitride
}

\author{
A K BASU and J MUKERJI \\ Central Glass and Ceramic Research Institute, Jadavpur, Calcutta 700 032, India \\ MS received 27 October 1989; revised 24 February 1990
}

\begin{abstract}
The authors examine the boric oxide-ammonia route with special stress on the yield and composition of the intermediate addition compound $(\mathrm{BN})_{x}\left(\mathrm{~B}_{2} \mathrm{O}_{3}\right)_{y}\left(\mathrm{NH}_{3}\right)_{z}$. It has been concluded that $\mathrm{B}_{2} \mathrm{O}_{3}$ and $\mathrm{NH}_{3}$ present in the addition compound formed between $350^{\circ} \mathrm{C}$ and $900^{\circ} \mathrm{C}$ cannot be further reacted to convert the $\mathrm{B}_{2} \mathrm{O}_{3}$ into $\mathrm{BN}$ and the BN yield remains at around $66 \%$. A formula $(\mathrm{BN})_{12-7}\left(\mathrm{~B}_{2} \mathrm{O}_{3}\right)_{7.5} \mathrm{NH}_{3}$ has been suggested for the addition compound.
\end{abstract}

Keywords. Boron nitride; synthesis; addition compound.

\section{Introduction}

Boron nitride is a white soapy substance. It has close resemblance to graphite in structure, in view of which it is also called white graphite. It has a high melting point $\left(3000^{\circ} \mathrm{C}\right.$ under high pressure of nitrogen) and low thermal conductivity of the nature of semiconductors. Its thermal shock resistance and chemical inertness to fused salts, slags etc make it a satisfactory refractory material for use as pressed articles in a number of special applications. In high temperature lubrication technology it finds use as sliding bearings. The material can also be used for conversion to cubic diamond-like material called 'borazon' with hardness similar to diamond, stable up to $2000^{\circ} \mathrm{C}$ and having insulating properties.

Amongst the routes available for the synthesis of boron nitride the boric oxideammonia route was investigated in this study.

The net reaction of formation of boron nitride may be depicted as,

$$
\mathrm{H}_{3} \mathrm{BO}_{3}+\mathrm{NH}_{3} \rightarrow \mathrm{BN}+3 \mathrm{H}_{2} \mathrm{O} \text {. }
$$

Economy et al (1969) have shown that the reaction takes place through the formation of a series of intermediate compounds whose stoichiometry could not be ascertained due to their instability. In the first step, ammonia reacts with boric oxide to form an addition compound $\left(\mathrm{B}_{2} \mathrm{O}_{3}\right)_{n} \mathrm{NH}_{3}$

$$
n \mathrm{~B}_{2} \mathrm{O}_{3} \underset{200^{\circ} \mathrm{C}}{\stackrel{\mathrm{NH}_{3}}{\longrightarrow}}\left(\mathrm{B}_{2} \mathrm{O}_{3}\right)_{n} \mathrm{NH}
$$

Above $350^{\circ} \mathrm{C}$ the addition compound $\left(\mathrm{B}_{2} \mathrm{O}_{3}\right)_{n} \mathrm{NH}_{3}$ reacts further with ammonia to form boron nitrogen rings with subsequent release of water.

$$
\left(\mathrm{B}_{2} \mathrm{O}_{3}\right)_{n} \mathrm{NH}_{3} \frac{\mathrm{NH}_{3}}{350^{\circ} \mathrm{C}}(\mathrm{BN})_{x}\left(\mathrm{~B}_{2} \mathrm{O}_{3}\right)_{y}\left(\mathrm{NH}_{3}\right)_{z}
$$

where $x, y, z$ are all variables depending upon reaction conditions such as time, ammonia concentration and rate of temperature rise.

The purpose of this work is to investigate the route of synthesis and to see how 
the yields may be increased. Attempts have also been made to identify the addition compound and to study its behaviour on heating.

\section{Experimental procedure}

\subsection{Preparation of material}

For the reaction of boric oxide and ammonia, an inert filler such as calcium orthophosphate is used. $\mathrm{B}_{2} \mathrm{O}_{3}$ melts at $\approx 450^{\circ} \mathrm{C}$, and forms a molten pool by the coalescence of small droplets thereby reducing the total surface available for reaction with ammonia gas. Therefore, an inert filler like calcium orthophosphate is used, so that the tiny droplets remain impregnated in the filler and do not get a chance to coalesce. The inert filler should be such that it does not react with either of the components of the reaction. In the present case, calcium orthophosphate and boron nitride from previous runs were used as filler.

The chief raw materials used were boric acid $(99.5 \%$ pure, SD's Laboratory Reagent, Bombay) and calcium phosphate, pure (Sarabhai Chemicals, Baroda, India). The raw materials in requisite proportions were wet-ground in water and dried. Pores were left in the dried mass to facilitate better penetration of ammonia during firing (Ingles and Popper 1960). Firing was done in stages up to $950^{\circ} \mathrm{C}$, and firing of the product was also carried out in stages between $950^{\circ} \mathrm{C}$ and $1400^{\circ} \mathrm{C}$. Heating up to $250^{\circ} \mathrm{C}$ was done in the presence of dry commercial nitrogen gas. Temperature was raised slowly at the rate of approximately $2^{\circ} \mathrm{C} / \mathrm{min}$ and the mass kept at this temperature up to $24 \mathrm{~h}$. After this, nitrogen gas flow was stopped and dry ammonia gas was switched on; temperature was raised at the previous rate up to $950^{\circ} \mathrm{C}$. Passage of ammonia also continued for another $24 \mathrm{~h}$. Large amounts of reaction and dehydration water were collected in bubblers kept in series with the furnace outlet.

The furnace used for first-stage heating was a transparent quartz tube open at both ends, wound externally by Kanthal wire capable of heating up to $1100^{\circ} \mathrm{C}$. Ends were closed with aluminium caps fitted with ' $O$ ' rings to make the furnace airtight. The whole arrangement was kept slightly inclined to facilitate water removal. The furnace had the usual attachments for indicating, controlling and recording temperature. The cooled mass from the furnace (described as $900^{\circ} \mathrm{C}$ mass in latter sections) was treated with $25 \%$ conc. hydrochloric acid to wash away the filler. For quick separations a magnetic stirrer-cum-heater was used. The process continued till sodium oxalate failed to produce any precipitate of calcium oxalate. The last traces of boric oxide was removed as ethyl borate by boiling with acidified ethyl alcohol.

Nitrogen and boron estimation was done by the method given by Parker and Healy (1970), Mukerji et al (1978) and Mitra and Sinha (1987). Phase identification was done by $\mathrm{X}$-ray diffraction and morphological studies were carried out using SEM.

\section{Results and discussion}

The results of a few synthesis runs are shown in table 1 . It may be seen that the 
Table 1. Yields of boron nitride obtained using calcium phosphate at different temperatures.

\begin{tabular}{lcc}
\hline $\begin{array}{l}\text { Temperature } \\
\left({ }^{\circ} \mathrm{C}\right)\end{array}$ & $\begin{array}{c}\text { Time of reaction } \\
(\mathrm{h})\end{array}$ & $\begin{array}{c}\text { Yield } \\
(\%)\end{array}$ \\
\hline 850 & 24 & $35 \cdot 0$ \\
950 & 24 & $66 \cdot 6$ \\
950 & 24 & $66 \cdot 4$ \\
900 & 24 & 63.6 \\
900 & 24 & 67.0 \\
\hline
\end{tabular}

Table 2. Yields of boron nitride using boron nitride from previous batches as filler. Temperature $=900^{\circ} \mathrm{C}$.

\begin{tabular}{lcc}
\hline $\mathrm{H}_{3} \mathrm{BO}_{3}:$ filler & $\begin{array}{c}\text { Time of reaction } \\
\text { (h) }\end{array}$ & $\begin{array}{c}\text { Yield } \\
(\%)\end{array}$ \\
\hline $5: 3$ & 24 & 14 \\
$1: 1$ & 24 & 32 \\
$1: 1$ & 24 & 35 \\
\hline
\end{tabular}

yield is never $100 \%$ but around $66 \%$. In other runs not quoted in the table the yield was found to vary, and was in all cases lower than $66 \%$. We decided to look further at the addition compound $(\mathrm{BN})_{x}\left(\mathrm{~B}_{2} \mathrm{O}_{3}\right)_{y}\left(\mathrm{NH}_{3}\right)_{z}$, supposed to be formed at $950^{\circ} \mathrm{C}$, and see if by heating it above $950^{\circ} \mathrm{C}$, the compound containing $\mathrm{B}_{2} \mathrm{O}_{3}$ and $\mathrm{NH}_{3}$, in addition to boron nitride already present in the compound, would yield more boron nitride.

The intermediate compound supposed to contain ammonia was treated with alkali. It gave off ammonia. In order to estimate this ammonia a small quantity was taken in a Kjeldahl flask, $40 \%$ sodium hydroxide was added, and it was then steam distilled. The ammonia given off with steam was absorbed in standard $25 \mathrm{ml}$ hydrochloride acid. The ammonia thus liberated was estimated to be $1.85 \%$. The presence of ammonia in the addition compound is thus established.

For the heat treatment of the $900^{\circ} \mathrm{C}$ mass, the materials in the form of small pellets were taken on an alumina boat in an impervious alumina tube furnace and heated at a rate of $300^{\circ} \mathrm{C} / \mathrm{h}$ up to $1100^{\circ} \mathrm{C}$. The soaking time was three hours, after which the furnace was cooled, and the material taken out and ground. The operation was repeated at $1200^{\circ} \mathrm{C}$ and $1500^{\circ} \mathrm{C}$. The ground $900,1100,1200$ and $1500^{\circ} \mathrm{C}$ masses were subjected to $\mathrm{X}$-ray diffraction analysis.

In contrast to the observations made during heating at $1100^{\circ} \mathrm{C}$ and $1200^{\circ} \mathrm{C}$, the material evolved copious fumes when heated at $1500^{\circ} \mathrm{C}$. For better observation this run was repeated thrice with the whole mass that was obtained at $900^{\circ} \mathrm{C}$. In addition to the fumes evolved, it was observed that the furnace when opened, contained a white product collected at the mouth, which caught fire as soon as it came into contact with air. The results of these runs have been tabulated in table 2 . It is seen from the table that the yield is around $57 \%$. It is slightly less than that 
quoted in table 1 . The white powder when subjected to chemical tests confirmed the presence of phosphorous.

The $900^{\circ} \mathrm{C} \mathrm{X}$-ray diffractogram (figure 1) shows the presence of $\mathrm{Ca}_{3}\left(\mathrm{PO}_{4}\right)_{2}$ and $\mathrm{Ca}_{2} \mathrm{P}_{2} \mathrm{O}_{7}$. The amount of free boron nitride was very low. The peak due to reflection from the $(002)$ plane appeared only as a hump and that due to the $(100)$ and (002) planes was almost insignificant. Only the reflection at $3 \cdot 36 \AA$ could confirm the presence of boron nitride. The general nature of the curve shows very low crystallinity of the materials present.

When the temperature is raised to 1100 and $1200^{\circ} \mathrm{C}, \mathrm{Ca}_{3}\left(\mathrm{PO}_{4}\right)_{2}$ remains in almost the same proportions. The change in the nature and the increase in the height of the peak are due to better crystallinity. The same is true for boron nitride (figure 1).

As the temperature is raised to $1500^{\circ} \mathrm{C}$ the amount of $\mathrm{Ca}_{3}\left(\mathrm{PO}_{4}\right)_{2}$ decreases appreciably in comparison to free boron nitride and a new phase of calcium borate is formed (figure 2). It is logical therefore to consider that the ammonia present in the addition compound is liberated around $1500^{\circ} \mathrm{C}$. At this temperature the calcium phosphate reacts with the addition compound which contains $\mathrm{B}_{2} \mathrm{O}_{3}$ to yield calcium borate and $\mathrm{P}_{2} \mathrm{O}_{5}$. The latter may be reduced to phosphorous by nascent hydrogen which is the decomposition product of ammonia. The phosphorous is collected as a white powder and burnt at the mouth of the furnace when it came in contact with air. Since the amount of $\mathrm{NH}_{3}$ is less in comparison to $\mathrm{P}_{2} \mathrm{O}_{5}$ it comes out of the furnace as fumes. In separate runs, calcium $o$-phosphate was heated in

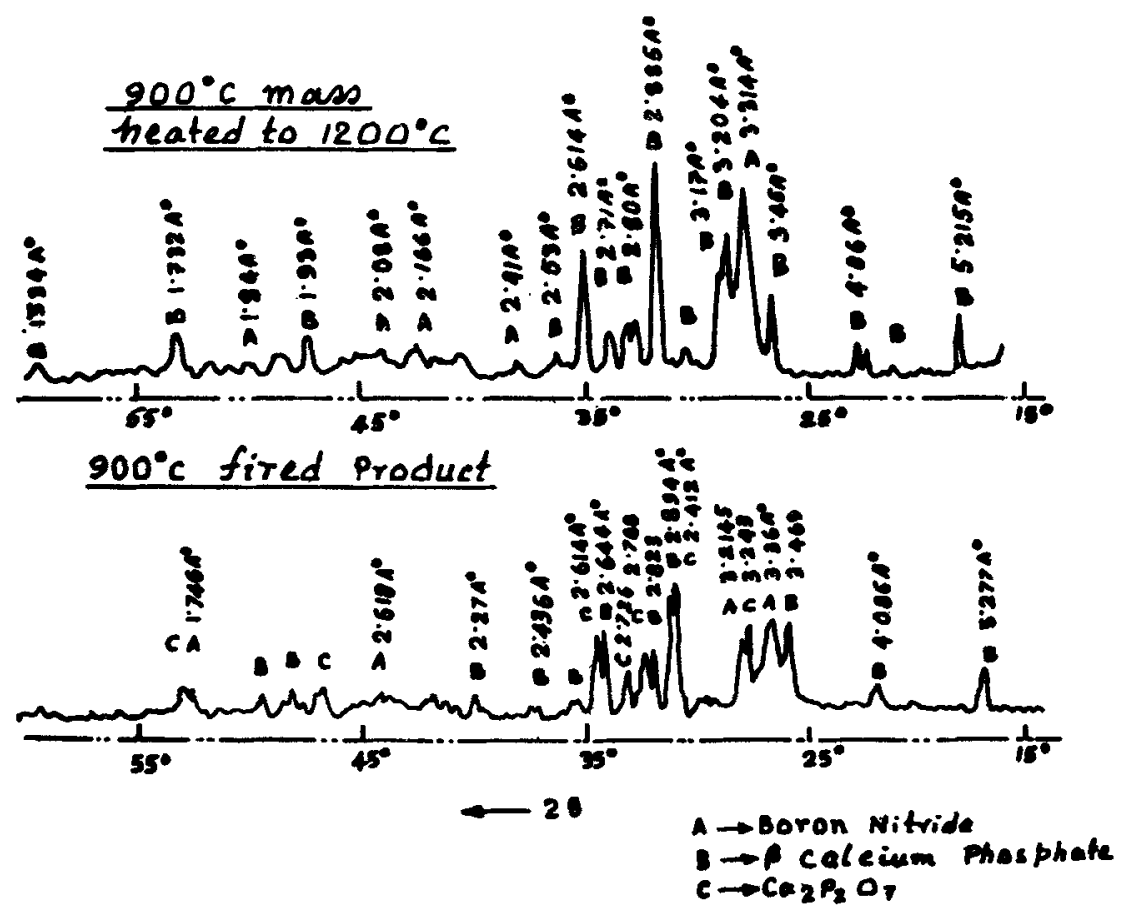

Figure 1. Comparison of XRDS of BN produced at $900^{\circ} \mathrm{C}$ and the same heated to $1200^{\circ} \mathrm{C}$. 


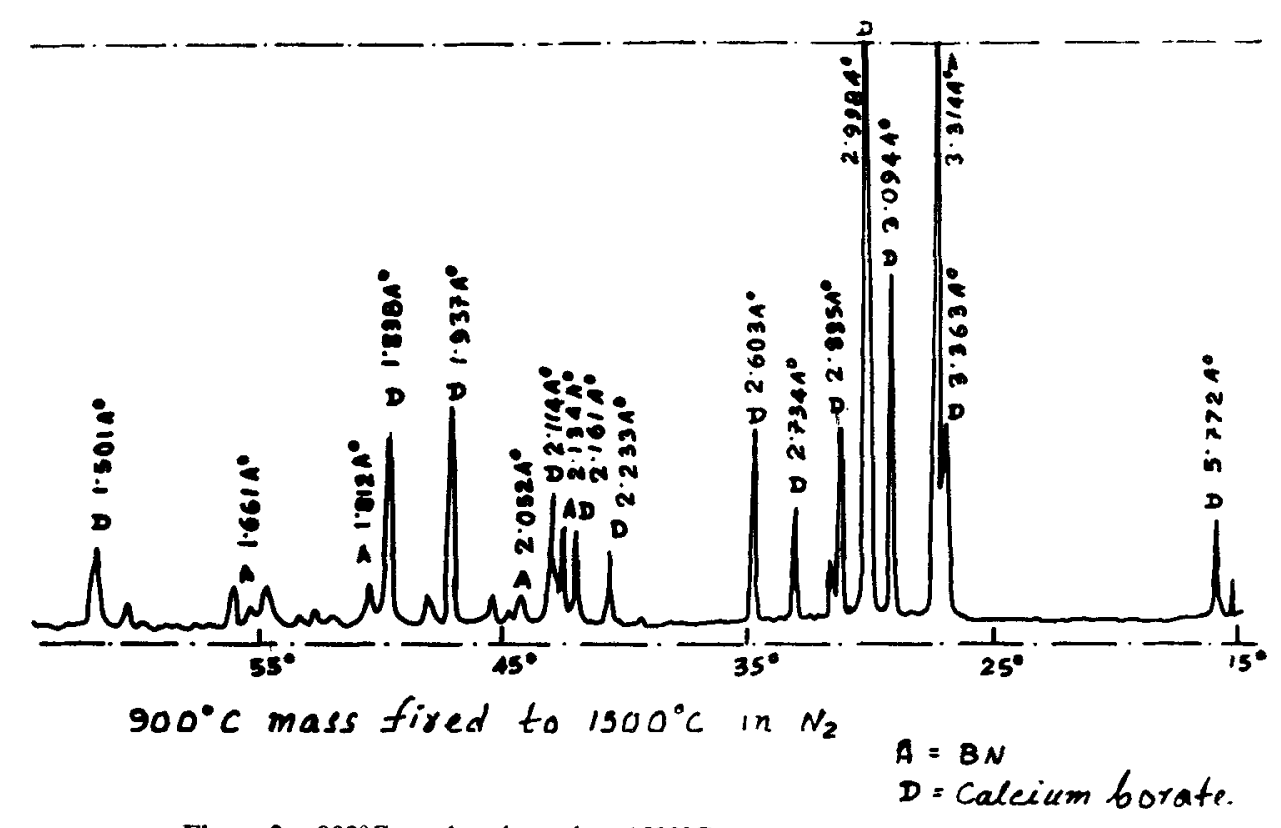

Figure 2. $900^{\circ} \mathrm{C}$ product heated to $1500^{\circ} \mathrm{C}$.

$\mathrm{NH}_{3}$ under identical conditions. The product when subjected to X-ray diffraction shows no change.

It has been stated earlier that the $900^{\circ} \mathrm{C}$ product gave approximately $2.0 \%$ ammonia when treated with strong alkali. Since the yields of boron nitride from acid-treated $900^{\circ} \mathrm{C}$ product and washed $1500^{\circ} \mathrm{C}$-fired mass are similar, it may be assumed that boron nitride produced by the reaction is entirely contained in the intermediate product $(\mathrm{BN})_{x}\left(\mathrm{~B}_{2} \mathrm{O}_{3}\right)_{y}\left(\mathrm{NH}_{3}\right)_{z}$. Thus the number of moles of boron nitride produced from the reaction is the final yield of the product. The amount of boric oxide in the addition compound is ascertained by difference.

The empirical formula for the addition compound may be written as,

$$
(\mathrm{BN})_{12 \cdot 7}\left(\mathrm{~B}_{2} \mathrm{O}_{3}\right)_{7 \cdot 5} \mathrm{NH}_{3} \text {. }
$$

In the X-ray diffractogram of the $900^{\circ} \mathrm{C}$ product no unidentified line which could be assigned to the proposed compound could be detected. The compound may therefore be present as an amorphous product.

\subsection{Use of boron nitride filler}

Boron nitride was also used as a filler with boric acid in different proportions. Yields obtained in these runs were not satisfactory and hence no further investigation was carried out. This has been shown in table 2 .

\subsection{SEM and chemical analysis of boron nitride}

The analysis of the boron nitride synthesized is shown in table 3 . It shows that the maximum yield of the product varies from 64 to $67 \%$. Impurities like 


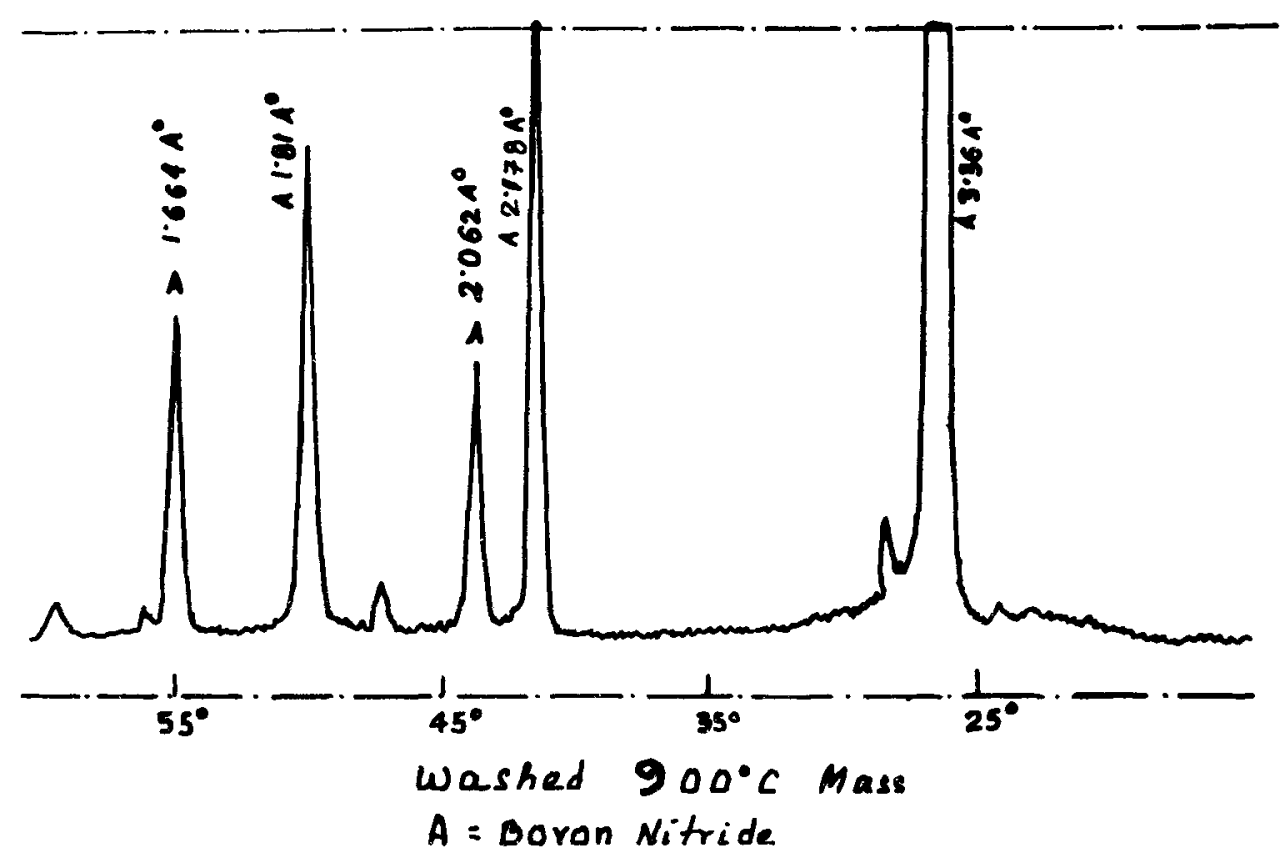

Figure 3. XRD of washed $900^{\circ} \mathrm{C}$ product (pure BN).

Table 3. Chemical analysis of the synthesised BN powders.

\begin{tabular}{|c|c|c|c|c|c|}
\hline $\begin{array}{l}\mathrm{B} \\
\%)\end{array}$ & $\begin{array}{l}\mathrm{Na}(\%) \\
\times 10^{-2}\end{array}$ & $\begin{array}{l}\mathrm{Ca}(\%) \\
\times 40^{-4}\end{array}$ & $\begin{array}{l}\mathrm{Fe}(\%) \\
\times 10^{-4}\end{array}$ & $\begin{array}{c}\text { Nitrogen calculated } \\
\text { from } \mathrm{B}(\%)\end{array}$ & $\begin{array}{c}\text { Nitrogen analysis } \\
\text { direct }\end{array}$ \\
\hline 40.80 & 1.8 & $2 \cdot 83$ & 3.42 & 52.54 & 55.4 \\
\hline $37 \cdot 37$ & $1 \cdot 4$ & $2 \cdot 60$ & $3 \cdot 16$ & $48 \cdot 39$ & 53.79 \\
\hline
\end{tabular}

sodium were estimated by flame photometer, $\mathrm{Ca}$ and $\mathrm{Fe}$ were determined by atomic absorption. Boron, estimated chemically, was less than that corresponding to the $\mathrm{N}_{2}$ estimated by the $\mathrm{Kjeldal}$ method. It is possible that there was a loss in $\mathrm{B}_{2} \mathrm{O}_{3}$ during chemical analysis due to the volatility of boron trifluoride as shown in table 3 .

The SEM photograph of boron nitride powder is shown in figure 4 . The hexagonal plates of boron nitride appear in the form of agglomerates. The particle size of the hexagonal plates may be less than one micron in size. BN was also produced by carbon reduction methods. The SEM photograph (figure 5) of this product shows well-separated hexagonal platelets with little agglomeration.

\section{Conclusion}

(1) An addition compound forms at $900^{\circ} \mathrm{C}$ which contains $2 \mathrm{wt} \%$ of ammonia and has the formula $(\mathrm{BN})_{12 \cdot 7}\left(\mathrm{~B}_{2} \mathrm{O}_{3}\right)_{7 \cdot 5} \mathrm{NH}_{3}$.

(2) If the ammoniated mass is heated to $1500^{\circ} \mathrm{C}$, the filler $\mathrm{Ca}_{3}\left(\mathrm{PO}_{4}\right)_{2}$ forms calcium borate and phosphorous. 

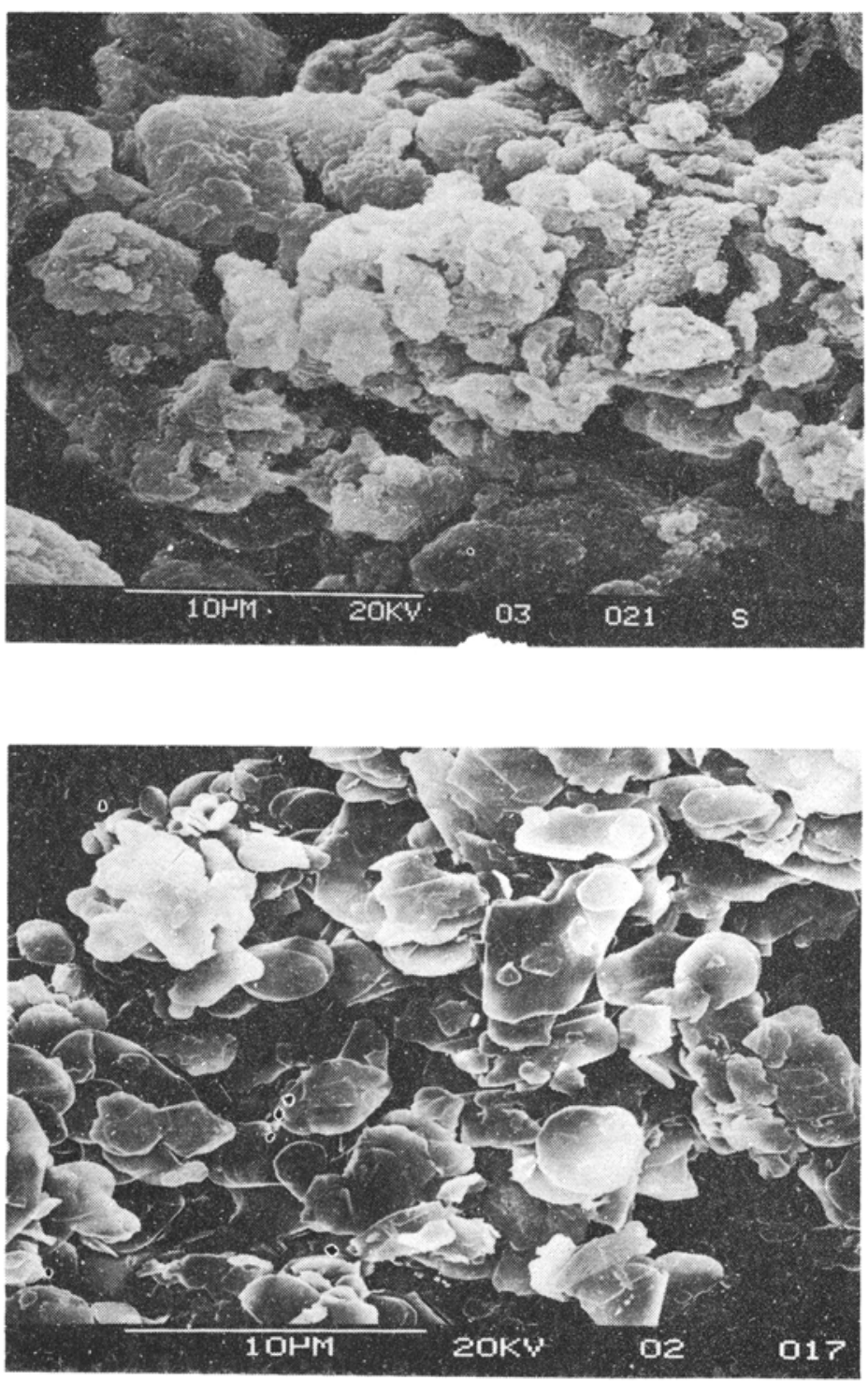

Figure 5. SEM photograph of BN made from Borax by carbon reduction method.

\section{Acknowledgements}

The authors acknowledge the contributions made by various members of the SEM and X-ray departments.

\section{References}

Economy J, Anderson R V and Matcovich V I 1969 Appl. Polym. Symp. 9347

Ingles T A and Popper P 1960 Special Ceramics (London: Heywood) p. 144 Mitra B and Sinha B C 1987 Trans. Indian Ceram. Soc. 46132

Mukerji J, Biswas S K and Dhargupta K K 1978 Indian J. Technol. 16156

Parker A and Healy C 1970 Analyst 91204 